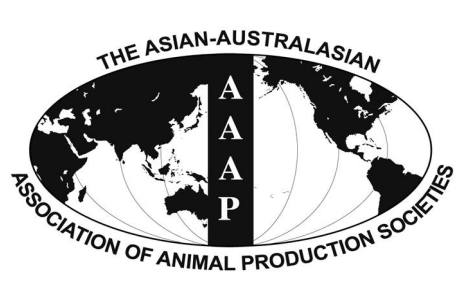

Open Access

Asian Australas. J. Anim. Sci.

Vol. 29, No. 6 : 793-800 June 2016

http://dx.doi.org/10.5713/ajas.15.0670

www.ajas.info

pISSN 1011-2367 elSSN 1976-5517

\title{
Testicular Characteristics and the Block to Spermatogenesis in Mature Hinny
}

\author{
Hongmei Han ${ }^{1}$, Aihong Wang ${ }^{1}$, Liming Liu ${ }^{1,2}$, Gaoping Zhao ${ }^{2}$, Jie Su${ }^{2}$, Biao Wang ${ }^{1}$, Yunxia Li ${ }^{1,2}$, \\ Jindun Zhang ${ }^{1}$, Baojiang $\mathrm{Wu}^{2}$, Wei Sun ${ }^{1,2}$, Shuxiang $\mathrm{Hu}^{1,2}$, Shuyu $\mathrm{Li}^{2}$, Lixia $\mathrm{Zhao}^{1,2}$, and Xihe $\mathrm{Li}^{1,2, *}$ \\ ${ }^{1}$ Research Center for Animal Genetic Resources of Mongolian Plateau, \\ Inner Mongolia University, Huhhot 010021, China
}

\begin{abstract}
Most hinnies (female donkey $\times$ male horse) and mules (female horse $\times$ male donkey) are sterile with few reports of equine fertile hybrids. The main cause of this sterility is thought to be a meiotic block to spermatogenesis and oogenesis. This study compared the developmental features of the testes and a histological analyses of spermatogenesis in a male hinny with those of a normal, fertile stallion and Jack donkey. Hinny testes showed a thicker tunica albuginea, fewer blood vessels and more connective tissue in the testis parenchyma than those of the stallion and Jack donkey. Although the mean number of seminiferous tubules was significantly higher in stallion and hinny than Jack donkey $(\mathrm{p}<0.01)$, the mean proportion of seminiferous tubules was lower in the hinny ( $<<0.01)$ which resulted in a smaller diameter of seminiferous tubules. The mean number of spermatogonia and spermatocytes per unit area were significantly lower in hinny testis $(\mathrm{p}<0.01)$ and no spermatids or mature spermatozoa cells were found during immunofluorescent analyses. These results indicated that defects in seminiferous tubule development and structure occur in the testis of hinnies. Furthermore, most spermatogonia and spermatocytes cease development in synapsis during mid-meiosis of spermatocytes, which results in a block to spermatogenesis that prevents the formation of spermatids and matured spermatozoa during meiosis in male hinnies. (Key Words: Hinny, Testis, Seminiferous Tubule, Spermatogenesis, Defect, Sterility)
\end{abstract}

\section{INTRODUCTION}

Mules (Equus mulus) and hinnies (Equus hinnus) are the sterile hybrid offspring that result from the mating of donkeys (Equus asinus) to horses (Equus caballus; Benirschke et al., 1962). The main cause of the sterility of mules and hinnies is probably related to failure of pairing of homologous chromosomes at meiosis during spermatogenesis (Wodsedalek, 1966; Taylor and Short, 1973; Chandley et al., 1974; 1975). A few studies have addressed fertility in female mules and hinnies (Rong et al., 1985; 1988; Ryder et al., 1985). Although the chromosomes in the very few fertile mules and hinnies are probably

\footnotetext{
* Corresponding Author: Xihe Li. Tel: +86-471-2530207, Fax: +86-471-2530207, E-mail: lixh@life.imu.edu.cn

${ }^{2}$ Inner Mongolia Saikexing Institute of Breeding and Reproductive Biotechnology in Domestic Animal, Huhhot 011517, China. Submitted Aug. 12, 2015; Revised Nov. 9, 2015; Accepted Dec. 6, 2015
}

similar to those of their parents (Anderson, 1939), more recent research on karyotypes of fertile mules and hinnies have demonstrated indirectly that the arrangement of their chromosomes differs from that of horses and donkeys (Zong and Fan, 1989; Henry et al., 1995). Because so few studies of fertile mules and hinnies have been reported, good scientific evidence explaining their reproductive ability has not yet been produced.

Basic testicle structure is highly conserved among vertebrates (Capel, 2000). Consequently, quantitative data can be used to investigate testis function and spermatogenesis (França and Russell, 1998). The spermatogenic process is nearly the same in all mammals (Sharpe, 1994), although germ cells at different stages of development exhibit different morphological characteristics during spermatogenesis (França and Russell, 1998). Therefore, these morphological characteristics are major criteria for stage identification of germ cells. A few studies 
have reported upon the spermatogenic process and testis morphometry in horses, donkeys and their hybrids (Hernández-Jáuregui and Monter, 1977; Nipken and Wrobel, 1997). However, these studies did not use quantitative methods and were therefore unable to elucidate testicular development and block to spermatogenesis in the hybrids.

Specific proteins are expressed at different stages of the spermatogenenic cycle. In human testis, the deleted in azoospermia-like (DAZL) protein is expressed in spermatogonia, early and late spermatocytes and postmeiotic cells (Yen et al., 1996). A recent study by Jung et al. (2014) showed that the DAZL protein is localized to the cytoplasm of spermatogonia and primary spermatocytes in stallion testis. During meiosis, the homologous chromosomes pair and recombine. The synaptonemal complex is essential during synapsis (Yang and Wang, 2009). As a DNA binding protein and structural component, synaptonemal complex protein 3 (SCP3) regulates homologous chromosome synapsis and pairing during meiosis in germ cells (Yuan et al., 2000). A lack of SCP3 can cause apoptosis and death of germ cells in mouse testes (Yuan et al., 2000). During spermatogenesis, somatic cell histones are replaced by sperm protamines in a multi-step process (Oliva and Dixon, 1991), the first step of which involves replacement of the histones with the transition nuclear proteins, transition protein 1 (TNP1) and TNP2, in round spermatids. Subsequently, the protamines replace TNP1 and TNP2 in elongating spermatids (Aoki et al., 2005). Hence DAZL, SCP3, and TNP1 can all be used as markers to distinguish spermatogonia, spermatocytes, spermatocytes in synapsis and spermatids.

To elucidate the mechanism of the reproductive block in hinnies, the present study used traditional histological analysis and recently developed immunofluorescent staining methods to characterize the development of the testes and to analyse spermatogenesis in the male hinny compared to stallion and Jack donkey.

\section{MATERIALS AND METHODS}

\begin{abstract}
Animal
The testes of a male hinny, stallion and Jack donkey, all 3 to 5 -years of age and in good health, were obtained from a local abattoir. The testes were maintained at $34^{\circ} \mathrm{C}$ in sterile $0.9 \%$ saline. After taking back to laboratory, they were washed twice with $75 \%$ ethanol and rinsed thrice in sterile $0.9 \%$ saline. The testes were then sectioned to enable the thickness of the tunica albuginea, the distribution of blood vessels and the colour of the parenchyma to be recorded. Small pieces $(1.0 \mathrm{~cm} \times 1.0 \mathrm{~cm} \times 0.5 \mathrm{~cm})$ of testis tissue were fixed in $4 \%$ formaldehyde $\geq 48 \mathrm{~h}$ for subsequent preparation of histological sections.
\end{abstract}

\section{Karyotyping of the hinny, stallion, and Jack donkey}

Small pieces of testis parenchyma were cultured in T25 cell culture flasks (Sigma-Aldrich, St Louis, MO, USA) and maintained at $37^{\circ} \mathrm{C}$ in a humidified $5 \% \mathrm{CO}_{2}$ atmosphere. The culture medium used was Alpha Minimal Essential Medium (MEM-Apha, GIBCO, Grand Island, NY, USA) containing $10 \%$ fetal bovine serum (FBS; HyClone, Logan, UT, USA) and 1\% penicillin/streptomycin (GIBCO, USA); the medium was changed every 2 to 3 days. When cells were cultured for 6 to 8 passages and covered $90 \%$ of the surface of the T25 cell culture flasks, they were prepared for metaphase chromosomes and analysis of their karyotypes as described previously (Zhang et al., 2011). Thirty well spread and moderately long chromosome sets per testis were observed microscopically $(\times 1,000)$ and photographed. Karyotype analysis was performed using AI (applied imaging) Cytovision 3.93 software as described previously (Zhang et al., 2011).

\section{Developmental characteristics and histology of testes}

Histological examinations were used to determine the mean number and percentage of seminiferous tubules (ST) per $\mathrm{mm}^{2}$ and the mean diameter and cross-sectional area of those ST. The blocks of fixed tissue were thoroughly washed with tap water and then dehydrated through a graded series of ethanol concentrations of $20 \%, 50 \%, 75 \%$, $85 \%, 95 \%(\times 2)$, and $100 \%$ for $1 \mathrm{~h}$ per concentration. Subsequently, they were cleaned twice in xylene for $1 \mathrm{~h}$ each and embedded in paraffin wax. Tissue sections were cut at 2 to $3 \mu \mathrm{m}$ and mounted on glass slides. These were then immersed in xylene twice, each for $15 \mathrm{~min}$, followed by a six-step rehydration through a graded series of ethanol. The rehydrated tissues were then stained with hematoxylin and eosin (H\&E) for $30 \mathrm{~min}$.

First, 100 areas from hinny, stallion and Jack donkey were selected randomly to count the mean number and percentage of that area occupied by tubules, per unit area $\left(660 / 1 \mathrm{~mm}^{2}\right.$ square method) under $100 \times$ and $200 \times$ magnifications. One hundred ST were selected to count the Sertoli cells, then 100 mostly round ST and Sertoli cell nuclears from each animal were selected to measure their mean diameter using an ocular micrometer. The formula $\pi \mathrm{r}^{2}$ was used to calculate ST area.

\section{Immunofluorescent analysis of different stages of germ cell development}

The objective of this immunofluorescent staining method was to distinguish spermatogonia, spermatocytes, spermatocytes in synapsis and spermatids during the spermatogenic cycle in the three species. Several germ cellspecific antibodies were used as follows: i) the spermatogonia and spermatocyte-specific antibody, DAZL; 
ii) the spermatocyte in synapsis-specific antibody, SCP3; iii) the spermaid-specific antibody, TNP1. Antigen retrieval was performed by incubating the tissue sections in sodium citrate buffer for $120 \mathrm{~min}$. The sections were then cooled to room temperature and washed three times in phosphatebuffered saline (PBS) for $5 \mathrm{~min}$. Next the sections were permeabilized in $0.3 \%(\mathrm{v} / \mathrm{v})$ TritonX-100 in PBS for $30 \mathrm{~min}$ at room temperature before being transferred to a humidified chamber and blocked in 10\% FBS in PBS for 40 $\min$ at $37^{\circ} \mathrm{C}$. Subsequently, the samples were incubated overnight at $4^{\circ} \mathrm{C}$ in a humidified chamber with the primary antibodies, which included i) goat polyclonal DAZL (Santa Cruz, CA, USA, sc-27333, 1/100), ii) rabbit polyclonal SCP3 (Abcam, Cambridge, MA, USA, ab85621, 1/200), and iii) rabbit polyclonal TNP1 (Abcam, Cambridge, MA, USA, ab73135, 1/200). Next day, slides were washed three times in $0.05 \%$ Tween-20/PBS $(\mathrm{v} / \mathrm{v})$ and treated for $45 \mathrm{~min}$ at room temperature with the respective secondary antibodies; rabbit anti-goat IgG (Alexa Fluor 488, Invitrogen, Carlsbad, CA, USA, 1/1,000) for DAZL and goat anti-rabbit IgG (FITC , Abcam, Cambridge, MA, USA, $1 / 400)$ for SCP3 and TNP1. The sections were washed three times in $0.05 \%$ Tween-20/PBS and Incubated in DAPI (Sigma, USA) nuclear stain. They were again washed three times in $0.05 \%$ Tween-20/PBS and then coverslipped using Vectashield mounting medium (Biyuntian, China). A confocal laser scanning microscopic imaging system was used to photograph some visual fields before $30 \mathrm{ST}$ from each individual animal were selected to calculate the mean numbers of germ cells at different stages of the spermatogenic cycle. Positive cells were stained green after treatment with three kinds of antibodies.

\section{Statistical analysis}

All the data are presented as means \pm standard error of the mean. T-test were conducted using the programme SPSS for Windows, Version 16.0 (SPSS Inc., Chicago, IL, USA). The highly significance level was $\mathrm{p}<0.01$.

\section{RESULTS}

\section{Karyotypes}

As shown in Figure 1, the karyotypes of the hinny, stallion and Jack donkey were $2 \mathrm{n}=63,2 \mathrm{n}=64$, and $2 \mathrm{n}=$ 62 , respectively. The $\mathrm{X}$ chromosome in hinny was the fourth longest in the maternal donkey. The Y chromosome was smallest chromosome in all three species.

\section{Structural characteristics and seminiferous tubule development of the testes}

The tunica albuginea was thinner in both the stallion and jackass than in the hinny. It was also obvious that the sections were rich in blood vessels in the stallion and Jack donkey testes, whereas they exhibited fewer blood vessels in the hinny.

The results of the histological cross sections of ST in the three species are shown in Figure 2 and Table 1. Analysis of 100 unit areas per animal showed the mean numbers of ST per unit area of $29.87 \pm 8.46$ for the hinny, $28.65 \pm 16.68$ for the stallion and $21.04 \pm 5.86$ for the Jack donkey. This mean number of ST per unit area was significantly higher in the hinny and stallion than the Jack donkey $(p<0.01)$. The mean proportion of total area of ST per unit area were $40.15 \% \pm$ $7.02 \%$ for the hinny, $47.66 \% \pm 6.07 \%$ for the stallion and $41.15 \% \pm 4.90 \%$ for the Jack donkey; the value was significantly higher in the stallion than in either the hinny or the Jack donkey $(\mathrm{p}<0.01)$. The mean diameters and area of 100 round or nearly round ST cross-sections for each species were $107.38 \pm 16.25 \mu \mathrm{m}$ and $9,051.41 \pm 207.29 \mu \mathrm{m}^{2}$ for the hinny, $133.46 \pm 15.92 \mu \mathrm{m}$ and $13,982 \pm 198.96 \mu \mathrm{m}^{2}$ for the stallion and $132.36 \pm 15.35 \mu \mathrm{m}$ and $13,752.54 \pm 184.96$ $\mu \mathrm{m}^{2}$ for the Jack donkey. The mean tubular diameter and area in the hinny were significantly lower than in the stallion and Jack donkey $(\mathrm{p}<0.01)$. However, there was considerable variation among tubule diameter in the hinny. Additionally, numerous observations revealed that the lumenae of the ST appeared more deflated, folded, and vacuolated in the hinny than in the stallion and Jack donkey. Early and late spermatids were regularly distributed in the
A

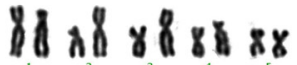

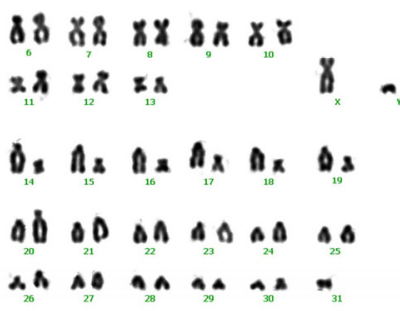

B
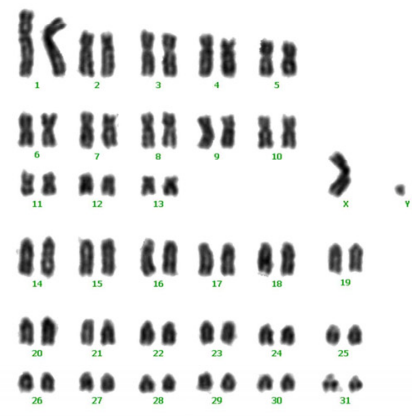

C
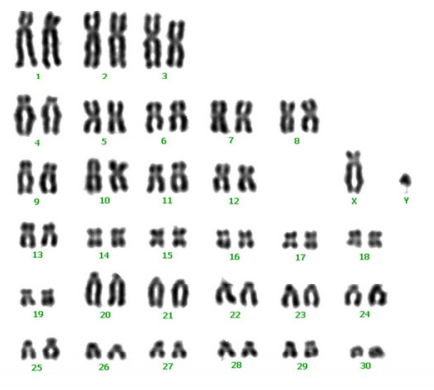

Figure 1. Hinny karyotype (A) compared with that of the stallion (B) and the Jack donkey (C). The number of chromosomes was $2 \mathrm{n}$ $=63(\mathrm{XY}), 2 \mathrm{n}=64(\mathrm{XY})$, and $2 \mathrm{n}=62(\mathrm{XY})$ in the hinny, stallion $(\mathrm{B})$ and Jack donkey, respectively. 

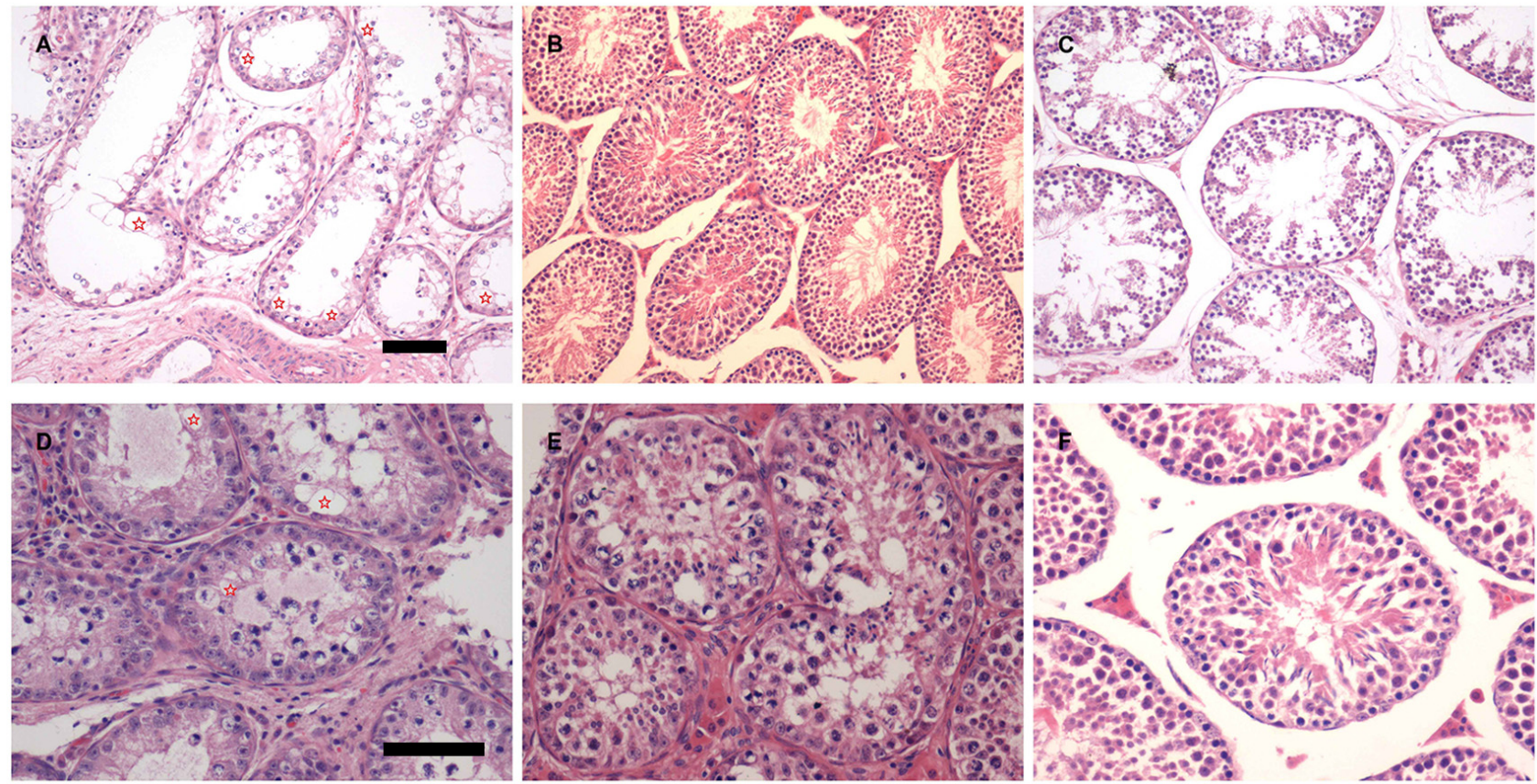

Figure 2. Developmental characteristics in the testes of the hinny, stallion and Jack donkey. The seminiferous tubules (ST) lumenae were more deflated, folded and vacuolated in the hinny (A and D) than in the stallion (B and E) and Jack donkey (C and F). There were fewer germ cells and they were more irregularly distributed in the hinny than in the stallion and Jack donkey. Asterisks were highlighting the vacuole of ST in hinny. Scale bar $=100 \mu \mathrm{m}$.

lumen of the tubules in the stallion and Jack donkey but not found in the hinny ST. Additionally, the number of Sertoli cells per ST and the mean diameter of Sertoli cell nuclears were $33.15 \pm 14.92$ and $9.37 \pm 1.26 \mu \mathrm{m}$ for the hinny, $27.02 \pm 12.34$ and $9.23 \pm 1.01 \mu \mathrm{m}$ for the stallion and $8.36 \pm 3.49$ and $9.73 \pm 1.39 \mu \mathrm{m}$ for the Jack donkey, respectively. The number of Sertoli cells per ST was significantly lower in the Jack donkey than either in the hinny or the stallion $(\mathrm{p}<0.01)$. However, the mean diameter of Sertoli cells nulear were higher in the Jack donkey than in the hinny and stallion $(\mathrm{p}<0.01)$.

\section{Result of germ cell immunofluorescent staining}

The results of immunofluorescent staining with the DAZL, SCP3, and TNP1 antibodies are shown in Table 2 and Figure 3. Positive staining with DAZL was observed in the testes of all three species. However, whereas these
DAZL-positive cells were distributed in a single-layer along the basement membrane of the ST in the hinny, they were multi-layered in the stallion and Jack donkey. Counts of stained spermatogonia and spermatocytes in the three species were $14 \pm 13$ for the hinny, $44 \pm 19$ for the stallion and $51 \pm 13$ for the Jack donkey. Thus, the number of spermatogonia and spermatocytes in the hinny was significantly lower than that in the stallion and Jack donkey $(\mathrm{p}<0.01)$. The SCP3 antibody was used to stain spermatocytes in synapsis. In the stallion and Jack donkey, the SCP3-positive cells were multi-layered, whereas they were single-layered in most of the ST in the hinny. The mean numbers of spermatocytes in synapsis were $5 \pm 9$ for the hinny, $13 \pm 12$ for the stallion, and $18 \pm 11$ for the Jack donkey. Thus there were significantly fewer spermatocytes in the hinny $(\mathrm{p}<0.01)$. TNP1 staining showed no spermatids in hinny, whereas they were multi-layered in both the

Table 1. Mean number, diameter, area and percentage of total area of ST per unit area in the hinny, stallion and Jack donkey

\begin{tabular}{|c|c|c|c|c|c|c|c|c|c|c|}
\hline \multirow{2}{*}{ Animal } & \multicolumn{4}{|c|}{ Mean number and proportion of area of ST } & \multicolumn{3}{|c|}{ Diameter and area of ST } & \multicolumn{3}{|c|}{$\begin{array}{l}\text { Mean number and diameter of Sertoli } \\
\text { cells }\end{array}$} \\
\hline & $\mathrm{N} 1^{1}$ & Mean & $\mathrm{N} 2^{1}$ & $\begin{array}{l}\text { Propor-tion } \\
(\%)\end{array}$ & $N 3^{1}$ & m) & Area $\left(\mu \mathrm{m}^{2}\right)$ & $\mathrm{N} 4^{2}$ & Mean number & $\begin{array}{l}\text { Mean diameter } \\
(\mu \mathrm{m})\end{array}$ \\
\hline Hinny & 100 & $29.87 \pm 8.46^{\mathrm{b}}$ & 100 & $40.15 \pm 7.02^{\mathrm{a}}$ & 100 & $107.38 \pm 16.25^{\mathrm{a}}$ & $9,051.41 \pm 207.29^{\mathrm{a}}$ & 100 & $33.15 \pm 14.92^{b}$ & $9.37 \pm 1.26^{\mathrm{a}}$ \\
\hline Stallion & 100 & $28.65 \pm 16.68^{\mathrm{b}}$ & 100 & $47.66 \pm 6.07^{\mathrm{b}}$ & 100 & $133.46 \pm 15.92^{\mathrm{b}}$ & $13,982.08 \pm 198.96^{\mathrm{b}}$ & 100 & $27.02 \pm 12.34^{\mathrm{b}}$ & $9.23 \pm 1.01^{\mathrm{a}}$ \\
\hline Jack donkey & 100 & $21.04 \pm 5.86^{\mathrm{a}}$ & 100 & $41.15 \pm 4.90^{\mathrm{a}}$ & 100 & $132.36 \pm 15.35^{\mathrm{b}}$ & $13,752.54 \pm 184.96^{\mathrm{b}}$ & 100 & $8.36 \pm 3.49^{\mathrm{a}}$ & $9.73 \pm 1.39^{\mathrm{b}}$ \\
\hline
\end{tabular}

ST, seminiferous tubule; $\pi r^{2}$, the formula of ST area cross-section.

Data are presented as means \pm standard error of the mean.

${ }^{1} \mathrm{~N} 1, \mathrm{~N} 2$, and $\mathrm{N} 3$ : the investigated number of seminiferous tubules per unit.

${ }^{2} \mathrm{~N} 4$ : the investigated number of seminiferous tubules and Sertoli cells.

${ }^{a, b}$ Different superscripts indicate significant differences $(p<0.01)$ between animals. 
Table 2. The comparison of germ cell and spermatogenesis in the hinny, stallion and Jack donkey

\begin{tabular}{|c|c|c|c|c|}
\hline \multirow{2}{*}{ Animal } & \multirow{2}{*}{ Number of ST } & \multicolumn{3}{|c|}{ Spermatogenic stages } \\
\hline & & Spermatogonia and spermatocytes & Spermatocytes in synapsis & Spermatids \\
\hline Hinny & 30 & $14 \pm 13^{\mathrm{a}}$ & $5 \pm 9^{\mathrm{a}}$ & $0^{\mathrm{a}}$ \\
\hline Stallion & 30 & $44 \pm 19^{b}$ & $13 \pm 12^{b}$ & $47 \pm 29^{b}$ \\
\hline Jack donkey & 30 & $51 \pm 13^{b}$ & $18 \pm 11^{b}$ & $50 \pm 36^{\mathrm{b}}$ \\
\hline
\end{tabular}

ST, seminiferous tubule

Data are presented as mean \pm standard error of the mean.

${ }^{\mathrm{a}, \mathrm{b}}$ Different superscripts indicate significant differences $(\mathrm{p}<0.01)$ between animals.

stallion and Jack donkey. Mean values of the spermatids were 0 for the hinny, $47 \pm 29$ for the stallion and $50 \pm 36$ for the Jack donkey.

\section{DISCUSSION}

This is the first comparative investigation of testicular structure and spermatogenesis in two equine species and the infertile hybrid, the hinny. Furthermore, a more detailed analysis of the stage of spermatogenesis block, as the cause of sterility in male hinny, was undertaken.

Previous studies compared the testis weight, seminiferous tubule length, germ cell development and numbers of Sertoli and Leydig cells and seminiferous epithelium cycle length in mules and donkeys (Neves et al., 2002) and a comparative morphometric analysis of mule, horse and donkey testes, which included assessing the hardness, weight and shape of the testes plus determining
$\mathbf{A}$

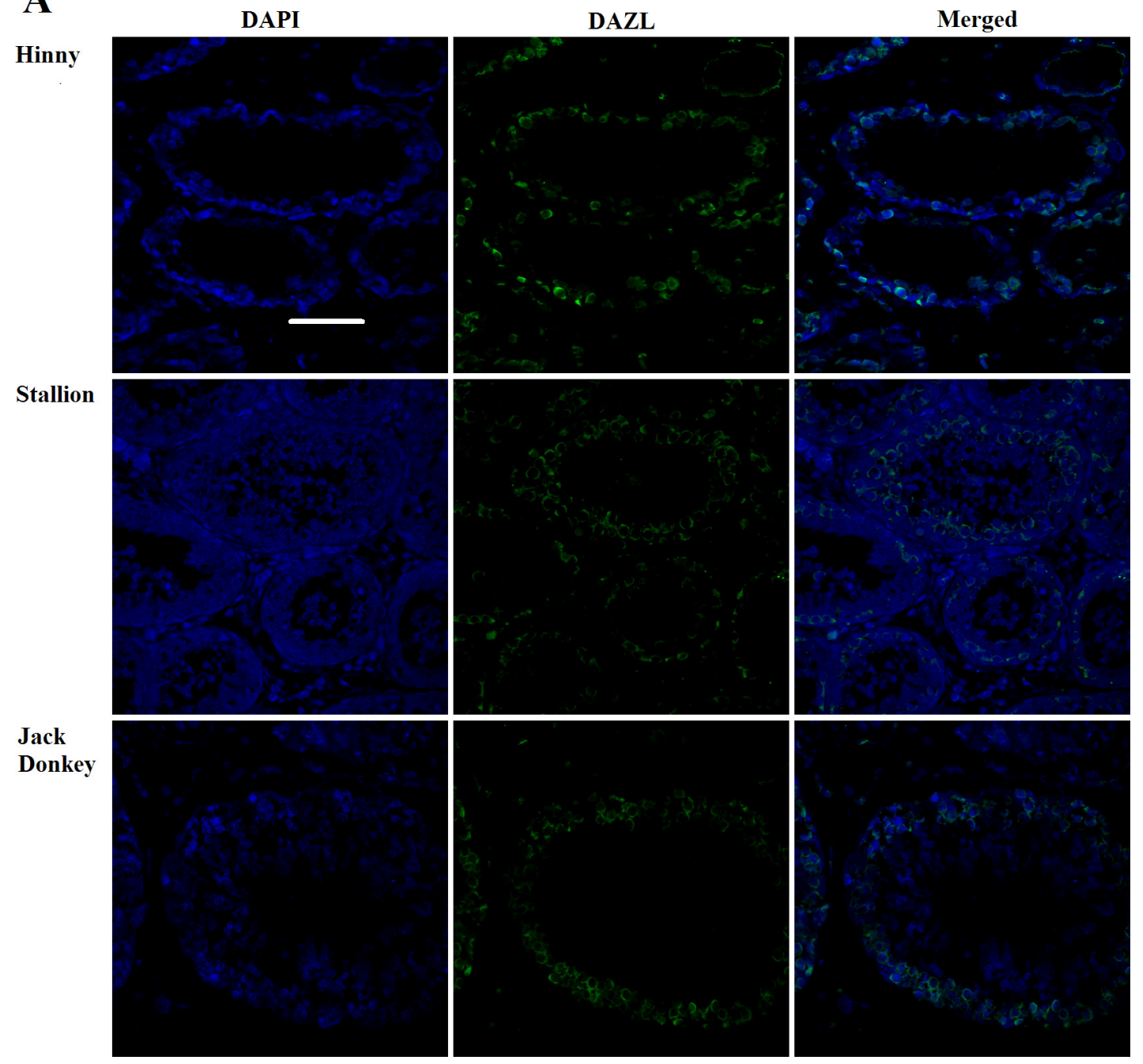

Figure 3. i) Immunofluorescent staining of germ cells and spermatogenesis in the hinny, stallion and Jack donkey. (A) The deleted in azoospermia-like (DAZL) was detected in the hinny, stallion and Jack donkey, respectively. Scale bar $=100 \mu \mathrm{m}$. 


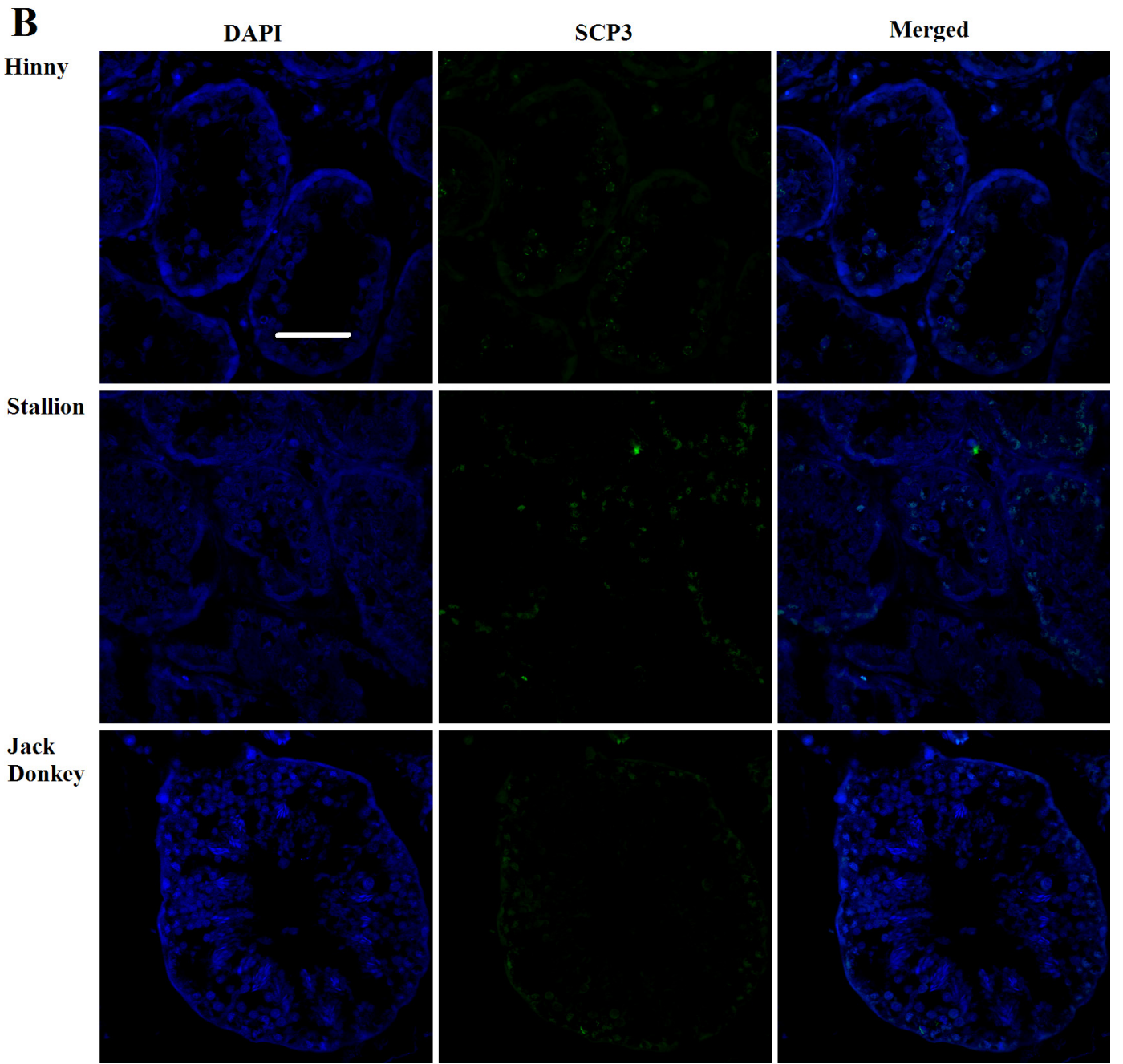

Figure 3. ii) Immunofluorescent staining of germ cells and spermatogenesis in the hinny, stallion and Jack donkey. (B) Synaptonemal complex protein 3 (SCP3)-positive cells were observed in all three species, but whereas they were multi-layered in the stallion and Jack donkey, they were fewer in number and were only single-layered in the hinny. Scale bar $=100 \mu \mathrm{m}$.

germ cell types plus the distribution of Sertoli and Leydig cells (Hernández-Jáuregui and Monter, 1977). In both, systematic measurements were not made of the number, size and area of seminiferous tubules nor the number of germ cells at different stages of development. Furthermore, the stage at which spermatogenesis is blocked in the mules and hinnies was not determined accurately.

The results of the present study highlighted some interesting differences in testis morphology between the hinny and the two parental species. For example, a thicker tunica albuginea, fewer blood vessels and more connective tissue were noted in the hinny testis. Moreover, the lumenae of the seminiferous tubules were more deflated, folded and vacuolated in the hinny. The morphological figures shown in Table 1 demonstrate that the mean number of seminiferous tubules per unit area was significantly lower in the Jack donkey but the figures were very similar in the hinny and stallion. Whereas seminiferous tubule diameter was lower in hinny than both of the stallion and Jack donkey, which resulted in the mean seminiferous tubule cross-sectional area being lower in the hinny than either in the stallion or Jack donkey. Neves et al. (2002) reported that seminiferous tubule diameter was significantly higher in donkeys than mules. The proportion of seminiferous tubules per unit area was similar in the hinny and Jack donkey but higher in the stallion, this result corresponds with the figures of the mean number and diameter in three species. Neves et al. (2002) reported that the number of Sertoli cells were similar in the mule and donkey, and diameter was higher in the donkey than in the mule. While the statistical analysis of Sertoli cell mean diameter in hinny and Jack donkey was consistent with Neves et al. (2002), the mean number was not.

The spermatogonia and spermatocytes were present in only a single layer in most of seminiferous tubules in the hinny. DAZL and SCP3 were expressed in the testes of all 


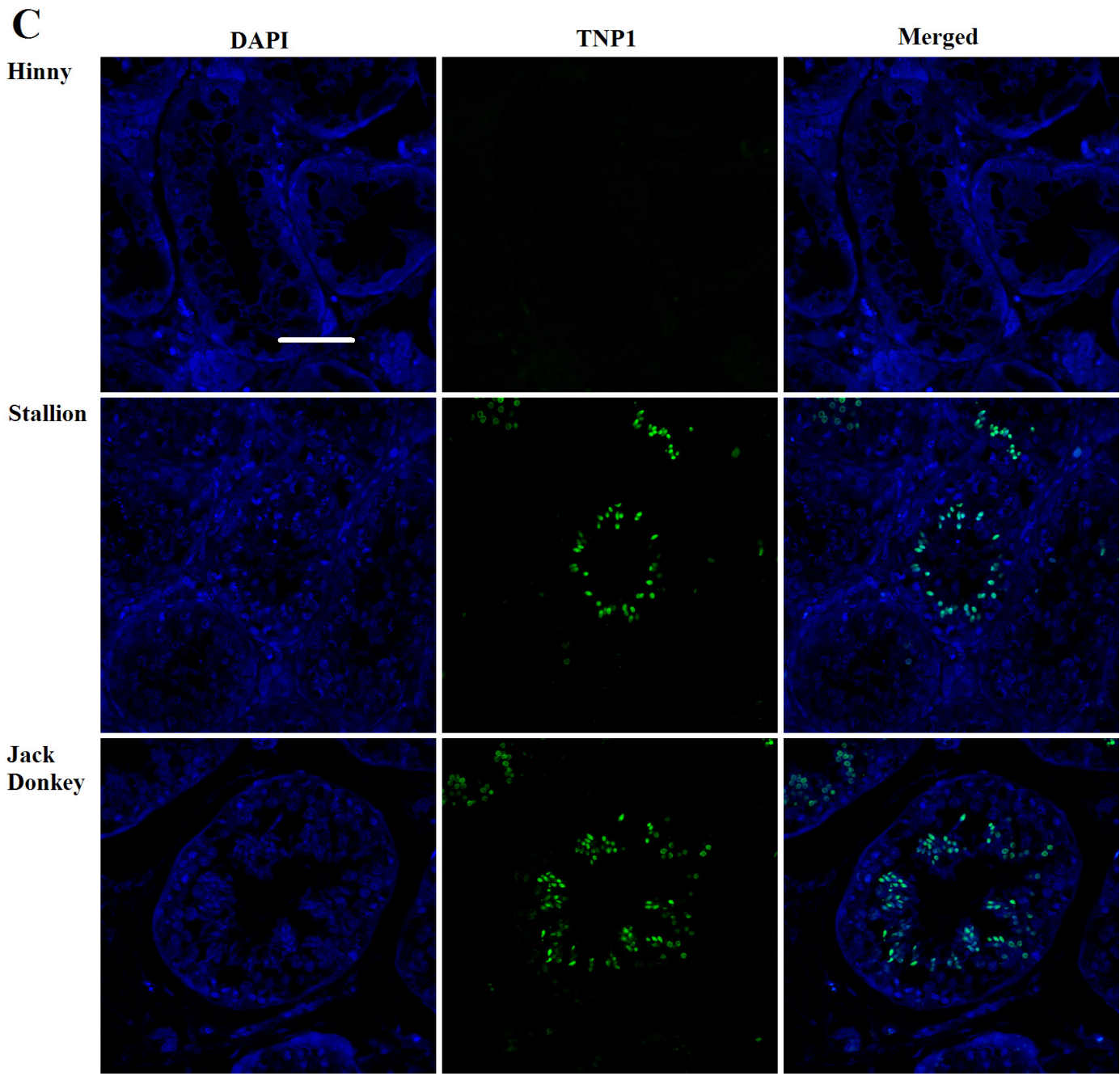

Figure 3. iii) Immunofluorescent staining of germ cells and spermatogenesis in the hinny, stallion and Jack donkey. (C) Transition protei n 1 (TNP1) staining was observed in both of the stallion and Jack donkey where these cells were round or elongating. But no TNP1stained cells were observed in the hinny. Scale bar $=100 \mu \mathrm{m}$.

three species but TNP1 was not exhibited in hinny indicating that spermatids were not present in the hinny testis (Chandley et al., 1974; 1975). These findings indicate that primary spermatocytes in the hinny could enter into synapsis but because of the failure of homologous chromosomes to pair (Henry et al., 1995; Zhao et al., 2005), they could not complete meiosis and therefore could not advance beyond the spermatocyte phase. Studies by Trujillo et al. (1969) and Zong and Fan (1989) showed that irregular shaped spermatozoa, such as some with a diamond-shaped head and others with an abnormally long and thin neck were occasionally found in three year old hinnies. This was not the case in the present study and the lack of spermatids was perhaps due to the individual differences between hinnies. The literature cites several potential causes of hybrid sterility (Borondi et al., 1998) but the most obvious of these, previously observed in mules by Taylor and Short (1973) is due to the different numbers of parental chromosomes
(Benirschke et al., 1962). Genetic incompatibility between parents (Borondi et al., 1998) and failure of pairing of sex chromosomes may also cause sterility (Forejt, 1996).

In conclusion, this study showed clear defects in testis and seminiferous tubule development in the hinny compared with the stallion and Jack donkey. The main cause of spermatogenic block in the hinny is probably a failure of pairing of homologous chromosomes which results in unfinished synapsis and incomplete meiosis. Therefore, the cells cannot advance beyond spermatocytes and spermatids.

\section{CONFLICT OF INTEREST}

We certify that there is no conflict of interest with any financial organization regarding the material discussed in the manuscript. 


\section{ACKNOWLEDGMENTS}

The work is supported by National Key Technologies $\mathrm{R}$ \& D Program (No. 2012BAD12B01) and Science and Technology Department of Inner Mongolia Autonomous Region (No.20121406, No.20130216).

\section{REFERENCES}

Anderson, W. S. 1939. Fertile mare mules. J. Hered. 30:549-551.

Aoki, V. W., L. Liu, and D. T. Carrell. 2005. Identification and evaluation of a novel sperm protamine abnormality in a population of infertile males. Hum. Reprod. 20:1298-1306.

Benirschke, K., L. E. Brownhill, and M. M. Beath. 1962. Somatic chromosomes of the horse, the donkey and their hybrids, the mule and the hinny. J. Reprod. Fertil. 4:319-326.

Borondi, P. M., M. B. Rogatcheva, A. I. Zhelezova, and S. Oda. 1998. Chromosome pairing in inter-racial hybrids of the house musk shrew (Suncus murinus, Insectivora, Soricidae). Genome 41:79-90

Capel, B. 2000. The battle of the sexes. Mech. Dev. 92:89-103.

Chandley, A. C., R. C. Jones, H. M. Dott, W. R. Allen, and R. V. Short. 1974. Meiosis in interspecific equine hybrids. Cytogenet. Genome. Res. 13:330-341.

Chandley, A. C., R. V. Short, and W. R. Allen. 1975. Cytogenetic studies of three equine hybrids. J. Reprod. Fertil. Suppl. 23: 365-370.

Forejt, J. 1996. Hybrid sterility in the mouse. Trends Genet. $12: 412-417$

França, L. R., T. Ogawa, M. R. Avarbock, R. L. Brinster, and L. D. Russel. 1998. Germ cell genotype controls cell cycle during spermatogenesis in the rat. Biol. Reprod. 59:1371-1377.

França, L. R. and L. D. Russell. 1998. The testis of domestic animals. In: Male Reproduction. A Multidisciplinary Overview (Eds. F. Martínez F and J. Regadera), edn 1. Churchill Livingstone, Madrid, Spain. pp. 197-219.

Henry, M., E. L. Gastal, L. E. L. Pinheriro, and S. E. F. Guimaraes. 1995. Mating pattern and chromosome analysis of a mule and her offspring. Biol. Reprod. Monograph Series 1:273-279.

Hernández-Jáuregui, P. and H. M. Monter. 1977. Fine structure of mule testes: light and electron microscopy study. Am. J. Vet. Res. 38:443-447.

Jung, H. J., H. Song, and M. J. Yoon. 2014. Stage-dependent DAZL localization in stallion germ cells. Anim. Reprod. Sci. 147:32-38.
Neves, E. S., H. Chiarini-Garcia, and L. R. França. 2002. Comparative testis morphometry and seminiferous epithelium cycle length in donkeys and mules. Biol. Reprod. 67:247-255.

Nipken, C. and K. H. Wrobel. 1997. A quantitative morphological study of age-related changes in the donkey testis in the period between puberty and senium. Andrologia 29:149-161.

Oliva, R. and G. H. Dixon. 1991. Vertebrate protamine genes and the histone-to-protamine replacement reaction. Prog. Nucl. Acid Res. Mol. Biol. 40:25-94.

Rong, R. H., H. D. Cai, X. Q. Yang, and J. Wei. 1985. Fertile mule in China and her unusual foal. J. R. Soc. Med. 78:821- 825.

Rong, R., A. C. Chandley, and J. Song. 1988. A fertile mule and hinny in China. Cytogenet. Genome Res. 47:134-139.

Ryder, O. A., I. G. Chemnic, A. T. Bowling, and K. Benirschke. 1985. Male mule foal qualifies as the offspring of a female mule and Jack donkey. J. Hered. 76:379-381.

Sharpe, R. M. 1994. Regulation of spermatogenesis. Physiol. Reprod. 1:1363-1434.

Taylor, M. J. and R. V. Short. 1973. Development of the germ cells in the ovary of the mule and hinny. J. Reprod. Fertil. 32:441445 .

Trujillo, J. M., S. Ohno, J. H. Jardine, and N. B. Atkins. 1969. Spermatogenesis in a male hinny: Histological and cytological studies. J. Hered. 60:79-84.

Wodsedalek, J. E. 1966. Causes of sterility in the mule. Biol. Bull. 30:1-56.

Yang, F. and P. J. Wang. 2009. The mammalian synaptonemal complex: a scaffold and beyond. Genome Dyn. 5:69-80.

Yen, P. H., N. N. Chai, and E. C. Salido. 1996. The human autosomal gene DAZLA: Testis specificity and a candidate for male infertility. Hum. Mol. Genet. 5:2013-2017.

Yuan, L., J. G. Liu, J. Zhao, E. Brundell, B. Daneholt, and C. Hoog. 2000. The murine $S C P 3$ gene is required for synaptonemal complex assembly, chromosome synapsis, and male fertility. Mol. Cell 5:73-83.

Zhang, J. N., Y. B. Liu, J. Su, Y. X. Li, W. Sun, L. X. Zhao, J. T. Guo, and X. H. Li. 2011. Karyotyping of Arab horse by Gbanding technique. Acta Agriculturae Boreali-sinica 26:101106

Zhao, C. J., G. C. Han, Y. H. Qin, and C. Wu. 2005. Differentiating among horse (Equus caballus), donkey (Equus asinus) and their hybrids with combined analysis of nuclear and mitochondrial gene polymorphism. J. Anim. Breed. Genet. 122:285-288

Zong, E. Z. and G. Q. Fan. 1989. The variety of sterility and gradual progression to fertility in hybrids of the horse and donkey. Heredity 62:393-406. 